\title{
Association of mixed use of electronic and conventional cigarettes and exposure to secondhand smoke with prediabetes
}

\section{Seung Hoon Kim}

Department of Preventive Medicine, Yonsei University College of Medicine

\section{Minah Park}

Institute of Health Services Research, Yonsei University

Gyu Ri Kim

Department of Preventive Medicine, Yonsei University College of Medicine

Sung-In Jang ( $\square$ JANGSI@yuhs.ac)

Department of Preventive Medicine, Yonsei University College of Medicine

\section{Research Article}

Keywords: prediabetes, $\mathrm{HbA1c}$, electronic cigarette, mixed use, secondhand smoke

Posted Date: April 1st, 2021

DOI: https://doi.org/10.21203/rs.3.rs-373449/v1

License: (a) (i) This work is licensed under a Creative Commons Attribution 4.0 International License. Read Full License

Version of Record: A version of this preprint was published at The Journal of Clinical Endocrinology \& Metabolism on August 26th, 2021. See the published version at https://doi.org/10.1210/clinem/dgab558. 


\section{Abstract \\ Objective}

To examine the association of mixed electronic and conventional cigarette use and exposure to secondhand smoke with prediabetes.

\section{Methods}

Data from the 2014-2018 Korean National Health and Nutrition Examination Survey were analyzed. Prediabetes was defined as an $\mathrm{HbA} 1 \mathrm{C}$ of $5.7-6.4 \%$. Participants were categorized according to type of cigarette use and secondhand smoke exposure. Multiple logistic regression analysis was performed.

\section{Results}

Of the 22,385 participants without diabetes, 6,735 had prediabetes. Mixed cigarette use was associated with a 1.57-fold increase in the odds of prediabetes when compared with never smoking without exposure to secondhand smoke (odds ratio $[\mathrm{OR}]=1.57,95 \%$ confidence interval $[\mathrm{Cl}]=1.31-1.87$ ), and a 1.27-fold increase when compared with conventional cigarette use only $(\mathrm{OR}=1.27,95 \% \mathrm{Cl}=1.09-1.49)$. Participants who were current non-smokers but mixed users in the past had an increased risk of prediabetes $(\mathrm{OR}=1.54,95 \% \mathrm{Cl}=1.06-2.23)$. However, there was no significant association between current non-smoking but only conventional cigarette use in the past and prediabetes. Among neversmokers, exposure to secondhand smoke significantly increased the risk of prediabetes $(O R=1.15,95 \%$ $\mathrm{Cl}=1.03-1.28)$.

\section{Conclusions}

Mixed use of electronic and conventional cigarettes and exposure to secondhand smoke increased the risk of prediabetes.

\section{Introduction}

In 2017, 425 million people were living with diabetes, a number that is expected to increase to 629 million by 2045 according to the latest estimates ${ }^{1}$. Diabetes can cause micro-vascular complications such as retinopathy, nephropathy, and neuropathy, as well as macro-vascular complications such as ischemic heart disease and stroke ${ }^{2,3}$. Therefore, the growing disease burden of diabetes is a major public health priority worldwide.

Previous studies have established that active smoking and exposure to secondhand smoke (SHS) are associated with an increased risk of insulin resistance and type 2 diabetes ${ }^{4-7}$. Although the smoking rate 
is steadily declining worldwide, $22.8 \%$ of the world's population smoked tobacco in 2020 , and more than 8 million people a year die from conditions related to tobacco use ${ }^{8}$. In Korea, the smoking rate was $22.3 \%$ in 2017 , with $38.1 \%$ of men falling under the "current smoker" category according to the Korea National Health and Nutrition Examination Survey. In recent years, high rates of smoking conventional cigarettes (c-cigarettes) have been accompanied by continuous increases in the use of electronic cigarettes (ecigarettes) and SHS exposure, thus representing a major public health problem ${ }^{9-11}$.

E-cigarettes that heat a liquid to deliver (usually) aerosols of nicotine and other flavors are often promoted as a safer alternative to c-cigarettes that burn tobacco to produce the nicotine aerosol ${ }^{12}$. Adults use e-cigarettes to reduce cigarette consumption or quit smoking, and some studies have mentioned the positive role that e-cigarettes can play in smoking cessation ${ }^{13}$. However, the risks of e-cigarettes remain to be clearly established. Particularly, research regarding the association between e-cigarette use and the risk of developing incident diabetes is limited.

Prediabetes is defined by the American Diabetes Association as follows: a fasting plasma glucose of $100-125 \mathrm{mg} / \mathrm{dL}$ or 2-h plasma glucose value during a 75-g oral glucose tolerance test of $140-199$ $\mathrm{mg} / \mathrm{dL}$, or hemoglobin $\mathrm{A} 1 \mathrm{c}(\mathrm{HbA} 1 \mathrm{c})$ levels of $5.7-6.4 \%{ }^{14}$. Prediabetes is a state in which the patient is at high risk for diabetes, with higher glucose levels than normal, and about $5-10 \%$ of people with prediabetes become diabetic annually ${ }^{15}$. Furthermore, prediabetes has been associated with multiple comorbidities such as composite cardiovascular disease, coronary heart disease, stroke, and all-cause mortality ${ }^{16}$. Thus, screening for prediabetes among non-diabetic individuals and identifying risk factors for prediabetes is an important public health task.

The purpose of this study was to investigate the association of smoking behavior and exposure to SHS with prediabetes, which can aid in predicting the incidence of type 2 diabetes in people who have no known history of diabetes.

\section{Methods}

\section{Study population and data}

This study used data obtained from the 2014 and 2018 Korean National Health and Nutrition Examination Survey (KNHANES). The KNHANES is a nationwide population-based survey designed to acquire information regarding the health and nutrition of people in South Korea. The survey is performed by the Korean Centers for Disease Control and Prevention (KCDC) and combines a health interview with a physical examination and nutrition survey. The KNHANES protocols were approved by the Institutional Review Board of the KCDC (IRB No. 2018-01-03-P-A), and the research complied with the tenets of the Declaration of Helsinki for medical research involving human subjects. Informed consent was obtained from all participants. 
A total of 39,199 participants were involved in the 2014-2018 KNHANES. In this study, participants aged $<19$ years, diagnosed with diabetes based on fasting plasma glucose levels over $126 \mathrm{mg} / \mathrm{dl}, \mathrm{HbA} 1 \mathrm{c}$ levels over $6.5 \%$, or the use of medication for diabetes were excluded. Furthermore, we excluded participants without data for the variables analyzed in this study. Finally, a total of 22,385 participants $(9,490$ men and 12,895 women) were selected for this study.

\section{Presence of prediabetes}

The presence of prediabetes was the primary outcome of this study. According to the definition of prediabetes as per the American Diabetes Association ${ }^{17}$, participants with an HbA1c cut-off of $5.7-6.4 \%$ were defined as having prediabetes. Fasting blood samples were collected from participants, and $\mathrm{HbA} 1 \mathrm{c}$ levels were assessed via high-performance liquid chromatography (HLC-723G7; Tosoh, Tokyo, Japan) ${ }^{18}$. Finally, patients with $\mathrm{HbA} 1 \mathrm{c}<5.7 \%$ were classified into the normal group, while those with $\mathrm{HbA} 1 \mathrm{c}$ of $5.7-$ $6.4 \%$ were classified into the prediabetes group.

\section{Smoking behavior and exposure to SHS}

The main independent variables were tobacco smoking behaviors and exposure to SHS. Smoking behavior was divided into four categories based on responses to questions regarding use of e-cigarettes or c-cigarettes over one's lifetime and those regarding exposure to SHS. mixed user of e- and c-cigarettes, c-cigarette user only, never-smoker with exposure to SHS, and never-smoker without exposure to SHS. Exposure to SHS was evaluated based on three questions, "In the last 7 days, have you ever breathed smoke from someone other than you who was smoking indoors at work?", "In the last 7 days, have you ever breathed smoke from someone other than you who was smoking indoors at home?", and "In the last 7 days, have you ever breathed smoke from someone other than you who was smoking indoors in a public place (except in designated smoking areas)?" The answers to these questions consisted only of "yes" or "no". Those who answered "yes" to even one of the three questions were defined as those exposed to SHS.

\section{Covariates}

The covariates for this study included sex, age, region (rural and metropolitan), educational level (under high school and university degree or above), occupation (white, pink, or blue collar and none), monthly household income quartiles, marital status, alcohol consumption, body mass index, muscle strengthening activity, aerobic activity, and history of chronic disease (hypertension, dyslipidemia, stroke, angina, myocardial infarction). Age was categorized into 10-year periods of $19-29,30-39,40-49,50-59,60-$ 69 , and $\geq 70$ years.

\section{Statistical analysis}

Chi-square tests were used to evaluate differences in the frequencies and proportions of categorical variables between participants with prediabetes and those without prediabetes. Multiple logistic 
regression analysis was performed to examine the association of smoking behavior and exposure to SHS with $\mathrm{HbA} 1 \mathrm{c}$ levels, after adjusting for covariates. The results are presented as odds ratios (ORs) and 95\% confidence intervals (Cls). Subgroup analyses were performed using sex and other covariates. All analyses were performed using Statistical Analysis Software (SAS, version 9.4, SAS, Inc., Cary, NC, USA), and $p<0.05$ was considered statistically significant.

\section{Results}

Table 1 presents the general characteristics of male and female participants with prediabetes. Among the 22,385 participants, $6,735(30 \%)$ had prediabetes. The number of participants who used mixed cigarette types was 1,628 (7.3\%), while the number who used c-cigarettes only was 6,954 (31.1\%). Among the 1,628 participants with mixed use, 393 (24.1\%) had prediabetes, compared to 2,303 (33.1\%) among the 6,954 participants who used only c-cigarettes. Among the 7,829 participants exposed to SHS, 2,245 $(28.7 \%)$ had prediabetes.

Table 2 shows the factors associated with prediabetes. Compared to those who never smoked without exposure to SHS, those with mixed e- and c-cigarette use, those who used only c-cigarettes, and those who never smoked but had been exposed to SHS exhibited an increased risk of prediabetes (mixed use group, $\mathrm{OR}=1.57,95 \% \mathrm{Cl}=1.31-1.87$; $\mathrm{c}$-cigarette use only group, $\mathrm{OR}=1.23,95 \% \mathrm{Cl}=1.10-1.38$; neversmoker with exposure to $\mathrm{SHS}, \mathrm{OR}=1.15,95 \% \mathrm{Cl}=1.03-1.28)$. Participants with mixed use of e- and ccigarettes exhibited increased odds of prediabetes when compared to users of c-cigarettes only (OR = $1.27,95 \% \mathrm{Cl}=1.09-1.49$, Fig. 1-A). The likelihood of developing prediabetes increased with age, body mass index (BMI), and muscle strengthening activity.

In the subgroup analysis of smoking behavior, participants who were current non-smokers but mixed users of e- and c-cigarettes in the past had significantly increased risk of prediabetes compared to participants who never smoked $(\mathrm{OR}=1.54,95 \% \mathrm{Cl}=1.06-2.23)$. However, there was no significant association between current non-smoker status but past use of c-cigarettes and prediabetes $(\mathrm{OR}=1.02$, $95 \% \mathrm{Cl}=0.90-1.16$, Fig. 1-B).

Table 3 presents the association between place of SHS exposure and prediabetes among never-smokers. Exposure to SHS at the workplace was associated with prediabetes in men $(\mathrm{OR}=1.58,95 \% \mathrm{Cl}=1.12-$ $2.24)$, whereas exposure to $\mathrm{SHS}$ at home was associated with prediabetes in women $(\mathrm{OR}=1.23,95 \% \mathrm{Cl}=$ $1.00-1.53)$.

Table 4 shows the results of subgroup analysis stratified by independent variables. Men who were mixed users, c-cigarette users only, and never-smokers with exposure to SHS had a significantly higher risk of prediabetes than never-smokers without exposure to SHS (mixed users: $\mathrm{OR}=1.75,95 \% \mathrm{Cl}=1.40-2.18$; ccigarettes only: $\mathrm{OR}=1.53,95 \% \mathrm{Cl}=1.29-1.83$; never-smokers with $\mathrm{SHS}$ exposure: $\mathrm{OR}=1.30,95 \% \mathrm{Cl}=$ 1.01-1.68). However, there was no significant association between smoking behavior and prediabetes among women. Participants who did not engage in aerobic activity with mixed use or use of c-cigarettes only had a higher risk of prediabetes than never-smokers (mixed users: $\mathrm{OR}=1.60,95 \% \mathrm{Cl}=1.32-1.95 ; \mathrm{C}^{-}$ 
cigarettes only: $\mathrm{OR}=1.27,95 \% \mathrm{Cl}=1.12-1.44)$. Among participants with obesity and normal/underweight participants, mixed use and c-cigarette use only were associated with a higher risk of prediabetes than never smoking without exposure to SHS.

\section{Discussion}

In the present study, we investigated the association of smoking behavior and exposure to SHS with prediabetes in the general population. Our findings indicated that there was a higher risk of prediabetes in both participants using a mixture of e- and c-cigarettes and those using c-cigarettes only than in those who were never-smokers. Furthermore, mixed use of e- and c-cigarettes was associated with an increased risk of prediabetes when compared to use of c-cigarettes only. Interestingly, we observed that participants who did not currently smoke but had smoked a mixture of e- and c-cigarettes in the past had a significantly increased risk of prediabetes, whereas participants who did not currently smoke but smoked only c-cigarettes in the past did not.

Several longitudinal studies have demonstrated that smoking is associated with diabetes ${ }^{19,20}$. However, few studies have confirmed a link between e-cigarette use and prediabetes ${ }^{21}$. Considering that adults often use a mixture of e- and c-cigarettes to reduce or quit c-cigarettes rather than smoking e-cigarettes alone, our research shows the association of e-cigarettes with prediabetes.

Although the mechanism by which the risk of prediabetes increases in mixed-type users remains unclear, several possible mechanisms can be suggested. First, nicotine may have an effect on the increased incidence of prediabetes. E-cigarette aerosol also contains highly oxidizing free-base nicotine, and the concentration of nicotine varies from product to product ${ }^{22,23}$. The nicotine dependence triggered by using e-cigarettes to quit cigarette smoking may have led mixed type users to smoke more e-or c-cigarettes. Further studies are required to evaluate the dose-response relationship with regard to e- and c-cigarette use and prediabetes. Second, the e-liquid component of e-cigarettes can affect the relationship between mixed use and prediabetes. Sugars and aldehydes found in e-liquid may have induced the development of prediabetes ${ }^{24}$. A previous in vitro study reported that e-cigarettes can affect body metabolism, affecting blood levels of lipids and inflammatory factors, resulting in decreased insulin sensitivity 25 . Furthermore, another study demonstrated that even e-liquid without nicotine induces hyperglycemia in rats, and that this disruption in glucose metabolism differs from that induced by e-liquid containing nicotine and nicotine alone ${ }^{26}$.

Our findings indicated that exposure to SHS among never-smokers was associated with a 1.15-fold increase in the risk of prediabetes when compared with non-exposure to SHS in both men and women. Our result is in line with the findings of previous studies showing that exposure to SHS is associated with the development of diabetes ${ }^{27,28}$. In addition, we observed differences in the places in which men and women are exposed to SHS. This result suggests that exposure to SHS in a space where people spend more of daily life may affects the risk of prediabetes. Future studies should examine the association of prediabetes according to the duration of exposure to SHS. 
In a subgroup analysis stratified by aerobic activity level, among those reporting aerobic inactivity, mixed use exhibited a stronger association with the risk of prediabetes than other types of use or exposure. Considering that there were no differences among the strata in the subgroup analysis of muscle strengthening activity level, aerobic exercise and mixed use of e- and c-cigarettes may exert a synergistic effect on the development of prediabetes. Our study is in line with a previous study reporting that structured exercise training, including aerobic exercise, is associated with a reduction of $\mathrm{HbA} 1 \mathrm{c}$ levels in patients with type 2 diabetes mellitus ${ }^{29,30}$.

This study has several limitations. First, the causal relationship between mixed use of e- and c-cigarettes and prediabetes should be interpreted cautiously, as our study was cross-sectional in nature. Second, the dose-response relationship for smoking and prediabetes could not be confirmed because the frequency of e-cigarette vaping and concentration of nicotine were not investigated in the survey. Third, data related to smoking behavior, exposure to SHS, and some covariates were collected through a self-reported survey, indicating that there may have been recall bias. Fourth, the effect of exposure to e-cigarette smoking on prediabetes has not been evaluated. Finally, we did not include a group of participants who used ecigarettes only.

Despite these limitations, this study has strengths. First, we investigated the association of smoking behavior and exposure to SHS with patients without diabetes who had a high probability of developing diabetes using $\mathrm{HbA} 1 \mathrm{c}$ levels, which reflect the average plasma glucose levels over the last 8-12 weeks. Since $\mathrm{HbA} 1 \mathrm{c}$ was tested through blood samples, the information provided can be considered reliable and valid. In addition, to the best of our knowledge, the present study is the first to evaluate the association of mixed use of e- and c-cigarettes and SHS with prediabetes. Lastly, our study is based on a nationally representative survey and random cluster sampling. This makes the data more reliable and representative of the Korean population. In addition, the results of the current study can be used as baseline motivators to establish nationalized policies or programs.

\section{Conclusion}

Despite many previous studies on the association between smoking and diabetes, the effects of ecigarette and SHS on insulin sensitivity or glucose metabolism have not been fully elucidated. In the current study, mixed use of e- and c-cigarettes was significantly associated with prediabetes when compared to use of c-cigarettes only. Additionally, among never-smokers, exposure to SHS increased the probability of developing prediabetes.

Further longitudinal and biological studies are required to evaluate the adverse health effects of this emerging way of smoking ("vaping" of e-cigarettes) and SHS. If the association between e-cigarette use and the risk of prediabetes is causal, regulation or education on e-cigarettes may help to reduce the risk of prediabetes, which can in turn reduce the worldwide burden of type 2 diabetes.

\section{Declarations}




\section{Data Availability}

All the KNHANES data used this study are available to the public and can be seen in the KNHANES official website (http://knhanes.cdc.go.kr/).

\section{Acknowledgements}

We would like to thank the Korean Centers for Disease Control (KCDC), which provided the data based on a nationwide survey.

\section{Author Contributions}

SHK and SIJ were responsible for the conception and design of the study. SHK performed the data curation and made contributions to analysis and interpretation of the data. SHK was drafted the manuscript. MP, GRK and SIJ were performed writing review and editing, and all authors read and approved the final version of the manuscript.

\section{Competing interests}

The authors declare no competing interests.

\section{Funding source:}

None

\section{References}

1. Forouhi, N. G. \& Wareham, N. J. J. M. Epidemiology of diabetes. Medicine. 47, 22-27 (2019).

2. Jørgensen, H., Nakayama, H., Raaschou, H. O. \& Olsen, T. S. Stroke in patients with diabetes. The Copenhagen Stroke Study. Stroke. 25, 1977-1984 (1994).

3. Matheus, A. S. et al. Impact of diabetes on cardiovascular disease: an update. International journal of hypertension 2013, 653789 (2013).

4. Chang, S. A. Smoking and type 2 diabetes mellitus. Diabetes \& metabolism journal. 36, 399-403 (2012).

5. Willi, C., Bodenmann, P., Ghali, W. A., Faris, P. D. \& Cornuz, J. Active smoking and the risk of type 2 diabetes: a systematic review and meta-analysis. Jama. 298, 2654-2664 (2007).

6. Lajous, M. et al. Childhood and adult secondhand smoke and type 2 diabetes in women. Diabetes care. 36, 2720-2725 (2013).

7. Jeon, J., Jung, K. J., Kimm, H. \& Jee, S. H. Changes in secondhand smoke exposure levels and risk of type 2 diabetes in middle age: the Korean Genome and Epidemiology Study (KoGES). BMJ open diabetes research \& care. 7, e000859 (2019). 
8. World Health Organiztion WHO global report on trends in prevalence of tobacco use 2000-2024, third edition https://www.who.int/publications/i/item/who-global-report-on-trends-in-prevalence-oftobacco-use-2000-2025-third-edition (2020).

9. Kang, S. H., Joo, J. H., Jang, S. I. \& Park, E. C. Association of exposure to secondhand smoke at home with early age at menarche in South Korea. Public health. 185, 144-149 (2020).

10. Jeon, C. et al. E-cigarettes, conventional cigarettes, and dual use in Korean adolescents and university students: Prevalence and risk factors. Drug and alcohol dependence. 168, 99-103 (2016).

11. Oberg, M., Jaakkola, M. S., Woodward, A. \& Peruga, A. \& Prüss-Ustün, A. Worldwide burden of disease from exposure to second-hand smoke: a retrospective analysis of data from 192 countries. Lancet (London, England). 377, 139-146 (2011).

12. Grana, R., Benowitz, N. \& Glantz, S. A. E-cigarettes: a scientific review. Circulation. 129, 1972-1986 (2014).

13. Bullen, C. et al. Electronic cigarettes for smoking cessation: a randomised controlled trial. Lancet (London, England). 382, 1629-1637 (2013).

14. 5. Prevention or Delay of Type 2 Diabetes: Standards of Medical Care in Diabetes-2018. Diabetes care. 41, S51-s54 (2018).

15. Tabák, A. G., Herder, C., Rathmann, W., Brunner, E. J. \& Kivimäki, M. Prediabetes: a high-risk state for diabetes development. Lancet. 379, 2279-2290 (2012).

16. Huang, Y., Cai, X., Mai, W., Li, M. \& Hu, Y. Association between prediabetes and risk of cardiovascular disease and all cause mortality: systematic review and meta-analysis. BMJ (Clinical research ed.). 355, i5953 (2016).

17. American Diabetes Association. Standards of medical care in diabetes-2013. Diabetes care. 36 Suppl (1), S11-66 (2013).

18. Baek, Y., Kim, M., Kim, G. R. \& Park, E. C. Cross-sectional study of the association between long working hours and pre-diabetes: 2010-2017 Korea national health and nutrition examination survey. BMJ open. 9, e033579 (2019).

19. Yeh, H. C., Duncan, B. B., Schmidt, M. I., Wang, N. Y. \& Brancati, F. L. Smoking, smoking cessation, and risk for type 2 diabetes mellitus: a cohort study. Annals of internal medicine. 152, 10-17 (2010).

20. Nishida, Y. et al. Influence of cigarette smoking and inflammatory gene polymorphisms on glycated hemoglobin in the Japanese general population. Preventive medicine reports. 3, 288-295 (2016).

21. Hoskinson, H. Effects of Chronic Electronic Cigarette Use on Glucose Metabolism https://search.proquest.com/docview/1958944760?accountid=15179 (2017).

22. Goel, R. et al. Highly reactive free radicals in electronic cigarette aerosols. Chemical research in toxicology. 28, 1675-1677 (2015).

23. Soneji, S. et al. Association Between Initial Use of e-Cigarettes and Subsequent Cigarette Smoking Among Adolescents and Young Adults: A Systematic Review and Meta-analysis. JAMA pediatrics. 171, 788-797 (2017). 
24. Fagan, P. et al. Sugar and Aldehyde Content in Flavored Electronic Cigarette Liquids. Nicotine \& tobacco research: official journal of the Society for Research on Nicotine and Tobacco. 20, 985-992 (2018).

25. Lan, K. et al. Electronic cigarette exposure on insulin sensitivity of ApoE gene knockout mice. Tobacco induced diseases. 18, 68 (2020).

26. El Golli, N. et al. Comparison between electronic cigarette refill liquid and nicotine on metabolic parameters in rats. Life sciences. 146, 131-138 (2016).

27. Zhang, L., Curhan, G. C., Hu, F. B., Rimm, E. B. \& Forman, J. P. Association between passive and active smoking and incident type 2 diabetes in women. Diabetes care. 34, 892-897 (2011).

28. Pan, A., Wang, Y., Talaei, M., Hu, F. B. \& Wu, T. Relation of active, passive, and quitting smoking with incident type 2 diabetes: a systematic review and meta-analysis. The lancet. Diabetes \& endocrinology. 3, 958-967 (2015).

29. Umpierre, D. et al. Physical activity advice only or structured exercise training and association with HbA1c levels in type 2 diabetes: a systematic review and meta-analysis. Jama. 305, 1790-1799 (2011).

30. Mikus, C. R. et al. Lowering physical activity impairs glycemic control in healthy volunteers. Medicine and science in sports and exercise. 44, 225-231 (2012).

\section{Tables}




\begin{tabular}{|c|c|c|c|c|c|c|c|}
\hline & \multicolumn{6}{|c|}{ Prediabetes $(5.7 \leq \mathrm{HbA1c} \leq 6.4)$} & \multirow{3}{*}{$P$-value } \\
\hline & \multicolumn{2}{|l|}{ Total } & \multicolumn{2}{|l|}{ Yes } & \multicolumn{2}{|l|}{ No } & \\
\hline & $\mathbf{N}$ & $\%$ & $\mathbf{N}$ & $\%$ & $\mathbf{N}$ & $\%$ & \\
\hline Total $(n=22,385)$ & 22,385 & 100 & 6,735 & 30 & 15,650 & 70 & \\
\hline Smoking behavior & & & & & & & $<0.0001$ \\
\hline Mixed user (e-cig. \& c-cig.) & 1,628 & 7.3 & 393 & 24.1 & 1,235 & 75.9 & \\
\hline Only c-cig. user & 6,954 & 31.1 & 2,303 & 33.1 & 4,651 & 66.9 & \\
\hline Never smoker with exposure to SHS & 4,181 & 18.7 & 1,106 & 26.5 & 3,075 & 73.5 & \\
\hline Never smoker w/o exposure to SHS & 9,622 & 43.0 & 2,933 & 30.5 & 6,689 & 69.5 & \\
\hline Sex & & & & & & & 0.484 \\
\hline Male & 9,490 & 42.4 & 2,879 & 30.3 & 6,611 & 69.7 & \\
\hline Female & 12,895 & 57.6 & 3,856 & 29.9 & 9,039 & 70.1 & \\
\hline Age & & & & & & & $<0.0001$ \\
\hline $19 \sim 29$ & 3,141 & 14.0 & 166 & 5.3 & 2,975 & 94.7 & \\
\hline $30 \sim 39$ & 4,016 & 17.9 & 613 & 15.3 & 3,403 & 84.7 & \\
\hline $40 \sim 49$ & 4,419 & 19.7 & 982 & 22.2 & 3,437 & 77.8 & \\
\hline $50 \sim 59$ & 4,394 & 19.6 & 1,681 & 38.3 & 2,713 & 61.7 & \\
\hline $60 \sim 69$ & 3,541 & 15.8 & 1,755 & 49.6 & 1,786 & 50.4 & \\
\hline $70+$ & 2,874 & 12.8 & 1,538 & 53.5 & 1,336 & 46.5 & \\
\hline Region & & & & & & & 0.7876 \\
\hline Rural & 9,791 & 43.7 & 2,955 & 30.2 & 6,836 & 69.8 & \\
\hline Metropolitan & 12,594 & 56.3 & 3,780 & 30.0 & 8,814 & 70.0 & \\
\hline Educational level & & & & & & & $<0.0001$ \\
\hline Under high school & 13,662 & 61.0 & 4,920 & 36.0 & 8,742 & 64.0 & \\
\hline College & 8,723 & 39.0 & 1,815 & 20.8 & 6,908 & 79.2 & \\
\hline Job & & & & & & & $<0.0001$ \\
\hline White collar & 5,951 & 26.6 & 1,192 & 20.0 & 4,759 & 80.0 & \\
\hline Pink collar & 2,994 & 13.4 & 865 & 28.9 & 2,129 & 71.1 & \\
\hline Blue collar & 5,093 & 22.8 & 1,914 & 37.6 & 3,179 & 62.4 & \\
\hline None & 8,347 & 37.3 & 2,764 & 33.1 & 5,583 & 66.9 & \\
\hline Household income & & & & & & & $<0.0001$ \\
\hline Low & 3,517 & 15.7 & 1,455 & 41.4 & 2,062 & 58.6 & \\
\hline Middle low & 5,382 & 24.0 & 1,752 & 32.6 & 3,630 & 67.4 & \\
\hline Middle high & 6,539 & 29.2 & 1,774 & 27.1 & 4,765 & 72.9 & \\
\hline High & 6,947 & 31.0 & 1,754 & 25.2 & 5,193 & 74.8 & \\
\hline Marital status & & & & & & & $<0.0001$ \\
\hline No & 6,790 & 30.3 & 1,615 & 23.8 & 5,175 & 76.2 & \\
\hline Yes & 15,595 & 69.7 & 5,120 & 32.8 & 10,475 & 67.2 & \\
\hline Alcohol consumption & & & & & & & $<0.0001$ \\
\hline $2 \sim 4$ times / week & 4,921 & 22.0 & 1,280 & 26.0 & 3,641 & 74.0 & \\
\hline $2 \sim 4$ times / month & 5,291 & 23.6 & 1,289 & 24.4 & 4,002 & 75.6 & \\
\hline Never or occasionally & 12,173 & 54.4 & 4,166 & 34.2 & 8,007 & 65.8 & \\
\hline Obesity status (BMI) & & & & & & & $<0.0001$ \\
\hline Obesity ( $\geq 25$ ) & 7,065 & 31.6 & 2,922 & 41.4 & 4,143 & 58.6 & \\
\hline Overweight (23-24.9) & 5,176 & 23.1 & 1,633 & 31.5 & 3,543 & 68.5 & \\
\hline Normal $(<23)$ & 10,144 & 45.3 & 2,180 & 21.5 & 7,964 & 78.5 & \\
\hline Muscle strengthening activity & & & & & & & $<0.0001$ \\
\hline
\end{tabular}




\begin{tabular}{|c|c|c|c|c|c|c|c|}
\hline No & 17,770 & 79.4 & 5,495 & 30.9 & 12,275 & 69.1 & \\
\hline Yes & 4,615 & 20.6 & 1,240 & 26.9 & 3,375 & 73.1 & \\
\hline Aerobic activity & & & & & & & $<0.0001$ \\
\hline No & 18,222 & 81.4 & 5,587 & 30.7 & 12,635 & 69.3 & \\
\hline Yes & 4,163 & 18.6 & 1,148 & 27.6 & 3,015 & 72.4 & \\
\hline Chronic disease $^{1}$ & & & & & & & $<0.0001$ \\
\hline$\geq 2$ & 2,692 & 12.0 & 1,396 & 51.9 & 1,296 & 48.1 & \\
\hline 1 & 5,985 & 26.7 & 2,538 & 42.4 & 3,447 & 57.6 & \\
\hline 0 & 13,708 & 61.2 & 2,801 & 20.4 & 10,907 & 79.6 & \\
\hline
\end{tabular}

\footnotetext{
${ }^{1}$ Defined as diagnosed diseases: hypertension, hyperlipidemia, stroke, and myocardial infarction or angina. The number of chronic diseases is the sum of the number of above diseases diagnosed.

Abbreviations: e-cig., electronic cigarette; c-cig., conventional cigarette; SHS, Secondhand smoke; w/o, without; BMI, body mass index
} 
Prediabetes(5.7 $\leq$ HbA1c $\leq 6.4)$

AOR $\quad 95 \% \mathrm{CI}$

\begin{tabular}{|c|c|c|c|c|}
\hline \multicolumn{5}{|l|}{ Smoking behavior } \\
\hline Mixed user (e-cig. \& c-cig.) & 1.57 & $(1.31$ & - & 1.87) \\
\hline Only c-cig. user & 1.23 & $(1.10$ & - & 1.38) \\
\hline Never smoker with exposure to SHS & 1.15 & $(1.03$ & - & 1.28) \\
\hline Never smoker w/o exposure to SHS & 1.00 & & - & \\
\hline \multicolumn{5}{|l|}{ Sex } \\
\hline Male & 1.00 & $(0.89$ & - & 1.11) \\
\hline Female & 1.00 & & - & \\
\hline \multicolumn{5}{|l|}{ Age } \\
\hline $19 \sim 29$ & 0.06 & $(0.05$ & - & $0.08)$ \\
\hline $30 \sim 39$ & 0.19 & $(0.16$ & - & $0.22)$ \\
\hline $40 \sim 49$ & 0.29 & $(0.25$ & - & $0.34)$ \\
\hline $50 \sim 59$ & 0.54 & $(0.47$ & - & $0.62)$ \\
\hline $60 \sim 69$ & 0.79 & $(0.70$ & - & $0.90)$ \\
\hline $70 \sim$ & 1.00 & & - & \\
\hline \multicolumn{5}{|l|}{ Region } \\
\hline Rurals & 0.85 & $(0.78$ & - & 0.93) \\
\hline Metropolitans & 1.00 & & - & \\
\hline \multicolumn{5}{|l|}{ Educational level } \\
\hline Under high school & 1.11 & $(1.01$ & - & 1.23) \\
\hline College & 1.00 & & - & \\
\hline \multicolumn{5}{|l|}{ Job } \\
\hline White & 0.99 & $(0.88$ & - & 1.10) \\
\hline Pink & 1.14 & $(1.01$ & - & 1.29) \\
\hline Blue & 1.13 & $(1.01$ & - & 1.26) \\
\hline None & 1.00 & & - & \\
\hline \multicolumn{5}{|l|}{ Household income } \\
\hline Low & 0.95 & $(0.84$ & - & 1.08) \\
\hline Middle low & 1.06 & $(0.95$ & - & 1.19) \\
\hline Middle high & 1.01 & $(0.92$ & - & 1.12) \\
\hline High & 1.00 & & - & \\
\hline \multicolumn{5}{|l|}{ Marital status } \\
\hline No & 0.95 & $(0.86$ & - & 1.05) \\
\hline Yes & 1.00 & & - & \\
\hline \multicolumn{5}{|l|}{ Drink } \\
\hline $2 \sim 4$ times / week & 0.71 & $(0.65$ & - & $0.79)$ \\
\hline $2 \sim 4$ times / month & 0.95 & $(0.86$ & - & 1.05) \\
\hline Never or occasionally & 1.00 & & - & \\
\hline \multicolumn{5}{|l|}{ Obesity Status (BMI) } \\
\hline Obesity $(\geq 25)$ & 2.25 & $(2.06$ & - & 2.47) \\
\hline Overweight (23-24.9) & 1.31 & $(1.18$ & - & 1.45) \\
\hline Normal (<23) & 1.00 & & - & \\
\hline \multicolumn{5}{|l|}{ Muscle strengthening activity } \\
\hline No & 1.11 & $(1.01$ & - & 1.23) \\
\hline
\end{tabular}


Yes

Aerobic activity

$\begin{array}{ll}\text { No } & 1.07 \\ \text { Yes } & 1.00\end{array}$

Chronic disease

$\begin{array}{lllll}\geq 2 & 1.76 & (1.56 & - & 1.98) \\ 1 & 1.44 & (1.31 & - & 1.58) \\ 0 & 1.00 & & & \end{array}$

${ }^{1}$ Defined as diagnosed diseases: hypertension, hyperlipidemia, stroke and myocardial infarction or angina. The number of chronic diseases is the sum of the number of diagnosed above diseases.

Abbreviations: e-cig., electronic cigarette; c-cig., conventional cigarette; SHS, Secondhand smoke; w/o, without; BMI, Body Mass Index;

Table 3. Association between place of secondhand smoke exposure and prediabetes among never smokers

\begin{tabular}{|c|c|c|c|c|c|c|c|c|c|c|c|c|}
\hline \multirow[t]{3}{*}{ Variables } & \multicolumn{12}{|c|}{ Prediabetes(5.7 $\leq$ HbA1c $\leq 6.4)$} \\
\hline & \multicolumn{4}{|l|}{ Total } & \multicolumn{4}{|l|}{ Male } & \multicolumn{4}{|c|}{ Women } \\
\hline & AOR & \multicolumn{3}{|c|}{$95 \% \mathrm{CI}$} & AOR & \multicolumn{3}{|c|}{$95 \% \mathrm{CI}$} & AOR & \multicolumn{3}{|c|}{$95 \% \mathrm{CI}$} \\
\hline \multicolumn{13}{|c|}{ Secondhand smoke } \\
\hline Workplace & 1.33 & $(1.11$ & - & 1.60) & 1.58 & $(1.12$ & - & 2.24) & 1.22 & $(0.99$ & - & 1.50) \\
\hline Home & 1.28 & $(1.03$ & - & 1.59) & 2.30 & $(0.91$ & - & $5.82)$ & 1.23 & $(1.00$ & - & 1.53) \\
\hline Public & 1.09 & $(0.94$ & - & 1.25) & 1.07 & $(0.75$ & - & 1.53) & 1.12 & $(0.96$ & - & 1.30) \\
\hline Never & 1.00 & & & & 1.00 & & & & 1.00 & & & \\
\hline
\end{tabular}

Adjusted for covariates

Abbreviations: AOR, adjusted odds ratio 
Table 4. Subgroup analysis stratified by independent variables

\begin{tabular}{|c|c|c|c|c|c|c|c|c|c|c|c|c|c|}
\hline \multirow[t]{4}{*}{ Variables } & \multicolumn{13}{|c|}{ Prediabetes $(5.7 \leq$ HbA1c $\leq 6.4)$} \\
\hline & \multicolumn{13}{|c|}{ Smoking behavior } \\
\hline & \multirow{2}{*}{$\begin{array}{l}\text { Never } \\
\text { smoker } \\
\text { w/o SHS } \\
\text { AOR }\end{array}$} & \multicolumn{4}{|c|}{$\begin{array}{l}\text { Never smoker with } \\
\text { SHS }\end{array}$} & \multicolumn{4}{|c|}{ Only c-cig. user } & \multicolumn{4}{|c|}{$\begin{array}{l}\text { Mixed user (e- and c- } \\
\text { cig.) }\end{array}$} \\
\hline & & AOR & $95 \% \mathrm{C}$ & & & $\overline{A O R}$ & $95 \% \mathrm{Cl}$ & & & AOR & $95 \% \mathrm{CI}$ & & \\
\hline \multicolumn{14}{|l|}{ Sex } \\
\hline Male & 1.00 & 1.30 & $(1.01$ & - & 1.68) & 1.53 & $(1.29$ & - & 1.83) & 1.75 & $(1.40$ & - & 2.18) \\
\hline Female & 1.00 & 1.17 & $(1.04$ & - & 1.33) & 1.05 & $(0.86$ & - & 1.27) & 1.28 & $(0.85$ & - & 1.94) \\
\hline \multicolumn{14}{|l|}{ Age } \\
\hline $19 \sim 29$ & 1.00 & 2.04 & $(1.29$ & - & $3.24)$ & 2.16 & $(1.27$ & - & 3.68) & 1.68 & $(0.92$ & - & 3.05) \\
\hline $30 \sim 39$ & 1.00 & 0.92 & $(0.68$ & - & 1.25) & 0.93 & $(0.70$ & - & 1.26) & 1.24 & $(0.87$ & - & 1.78) \\
\hline $40 \sim 49$ & 1.00 & 1.11 & $(0.88$ & - & 1.40) & 1.37 & $(1.07$ & - & 1.74) & 1.37 & $(0.98$ & - & 1.94) \\
\hline $50 \sim 59$ & 1.00 & 1.15 & $(0.95$ & - & 1.39) & 1.29 & $(1.01$ & - & 1.64) & 2.05 & $(1.35$ & - & $3.12)$ \\
\hline $60 \sim 69$ & 1.00 & 1.27 & $(1.00$ & - & 1.61) & 1.38 & $(1.03$ & - & 1.84) & 1.40 & $(0.78$ & - & 2.50) \\
\hline $70 \sim$ & 1.00 & 1.29 & $(0.93$ & - & 1.78) & 1.53 & $(1.16$ & - & 2.02) & 2.63 & $(1.31$ & - & 5.30) \\
\hline \multicolumn{14}{|l|}{ Region } \\
\hline Rurals & 1.00 & 1.27 & $(1.08$ & - & $1.50)$ & 1.22 & $(1.03$ & - & 1.44) & 1.46 & $(1.12$ & - & 1.90) \\
\hline Metropolitans & 1.00 & 1.08 & $(0.94$ & - & 1.23) & 1.24 & $(1.05$ & - & 1.45) & 1.63 & $(1.28$ & - & 2.08) \\
\hline \multicolumn{14}{|l|}{ Educational level } \\
\hline Under high school & 1.00 & 1.15 & $(1.01$ & - & 1.31) & 1.31 & $(1.14$ & - & 1.52) & 1.53 & $(1.20$ & - & 1.96) \\
\hline College & 1.00 & 1.13 & $(0.94$ & - & 1.36) & 1.08 & $(0.89$ & - & 1.31) & 1.53 & $(1.19$ & - & 1.98) \\
\hline \multicolumn{14}{|l|}{ Job } \\
\hline White & 1.00 & 1.15 & $(0.90$ & - & 1.45) & 1.19 & $(0.95$ & - & 1.49) & 1.38 & $(1.02$ & - & 1.87) \\
\hline Pink & 1.00 & 1.35 & $(1.04$ & - & 1.74) & 0.95 & $(0.69$ & - & 1.31) & 1.64 & $(1.06$ & - & 2.53) \\
\hline Blue & 1.00 & 1.27 & $(1.01$ & - & 1.60) & 1.58 & $(1.24$ & - & 2.01) & 1.72 & $(1.20$ & - & 2.46) \\
\hline None & 1.00 & 1.01 & $(0.86$ & - & 1.20) & 1.14 & $(0.94$ & - & 1.39) & 1.71 & $(1.14$ & - & 2.55) \\
\hline \multicolumn{14}{|l|}{ Household income } \\
\hline Low & 1.00 & 1.11 & $(0.84$ & - & 1.48) & 1.29 & $(0.98$ & - & 1.71) & 2.09 & $(1.20$ & - & 3.63) \\
\hline Middle low & 1.00 & 1.29 & $(1.04$ & - & 1.59) & 1.39 & $(1.12$ & - & 1.73) & 1.80 & $(1.27$ & - & 2.55) \\
\hline Middle high & 1.00 & 1.00 & $(0.82$ & - & 1.22) & 1.20 & $(0.97$ & - & 1.49) & 1.26 & $(0.91$ & - & 1.73) \\
\hline High & 1.00 & 1.16 & $(0.97$ & - & 1.40) & 1.07 & $(0.85$ & - & 1.34) & 1.48 & $(1.08$ & - & $2.04)$ \\
\hline \multicolumn{14}{|l|}{ Marital status } \\
\hline No & 1.00 & 1.29 & $(1.02$ & - & 1.62) & 1.33 & $(1.06$ & - & 1.67) & 1.85 & $(1.36$ & - & 2.53) \\
\hline Yes & 1.00 & 1.11 & $(0.98$ & - & 1.25) & 1.19 & $(1.04$ & - & 1.36) & 1.44 & $(1.15$ & - & 1.79) \\
\hline \multicolumn{14}{|l|}{ Drink } \\
\hline $2 \sim 4$ times / week & 1.00 & 1.24 & $(0.88$ & - & 1.73) & 1.41 & $(1.09$ & - & 1.82) & 1.47 & $(1.06$ & - & $2.04)$ \\
\hline $\begin{array}{l}2 \sim 4 \text { times / } \\
\text { month }\end{array}$ & 1.00 & 1.39 & $(1.10$ & - & 1.75) & 1.18 & $(0.94$ & - & 1.48) & 1.48 & $(1.08$ & - & 2.02) \\
\hline $\begin{array}{c}\text { Never or } \\
\text { occasionally }\end{array}$ & 1.00 & 1.07 & $(0.94$ & - & 1.22) & 1.24 & $(1.06$ & - & 1.45) & 1.91 & $(1.40$ & - & 2.62) \\
\hline \multicolumn{14}{|l|}{ Obesity Status (BMI) } \\
\hline Obesity ( $\geq 25$ ) & 1.00 & 1.12 & $(0.93$ & - & 1.34) & 1.25 & $(1.04$ & - & 1.51) & 1.59 & $(1.21$ & - & 2.08) \\
\hline $\begin{array}{l}\text { Overweight (23- } \\
24.9 \text { ) }\end{array}$ & 1.00 & 1.18 & $(0.95$ & - & 1.46) & 1.12 & $(0.88$ & - & 1.43) & 1.35 & $(0.94$ & - & 1.92) \\
\hline Normal (<23) & 1.00 & 1.15 & $(0.97$ & - & 1.36) & 1.32 & $(1.09$ & - & 1.59) & 1.59 & $(1.18$ & - & 2.14) \\
\hline
\end{tabular}




\begin{tabular}{|c|c|c|c|c|c|c|c|c|c|c|c|c|c|}
\hline No & 1.00 & 1.15 & (1.02 & - & 1.29) & 1.17 & (1.03 & - & 1.34) & 1.55 & $(1.26$ & - & 1.90) \\
\hline Yes & 1.00 & 1.14 & $(0.88$ & - & 1.46) & 1.46 & (1.15 & - & 1.86) & 1.52 & (1.05 & - & 2.20) \\
\hline \multicolumn{14}{|c|}{ Aerobic activity } \\
\hline No & 1.00 & 1.20 & (1.07 & - & 1.35) & 1.27 & (1.12 & - & 1.44) & 1.60 & (1.32 & - & 1.95) \\
\hline Yes & 1.00 & 0.94 & $(0.73$ & - & 1.20) & 1.11 & $(0.84$ & - & 1.47) & 1.41 & $(0.89$ & - & 2.24) \\
\hline \multicolumn{14}{|c|}{ Chronic disease } \\
\hline$\geq 2$ & 1.00 & 1.07 & $(0.80$ & - & 1.42) & 1.20 & $(0.88$ & - & 1.62) & 1.41 & $(0.87$ & - & 2.28) \\
\hline 1 & 1.00 & 1.19 & $(0.98$ & - & 1.44) & 1.31 & (1.08 & - & 1.60) & 1.45 & (1.06 & - & 1.98) \\
\hline 0 & 1.00 & 1.15 & $(1.00$ & - & 1.33) & 1.22 & (1.04 & - & 1.43) & 1.62 & $(1.30$ & - & 2.03) \\
\hline
\end{tabular}

Abbreviations: AOR, adjusted odds ratio; e-cig., electronic cigarette; c-cig., conventional cigarette; SHS, Secondhand smoke; w/o, without; BMI, Body Mass Index;

\section{Figures}


(A)

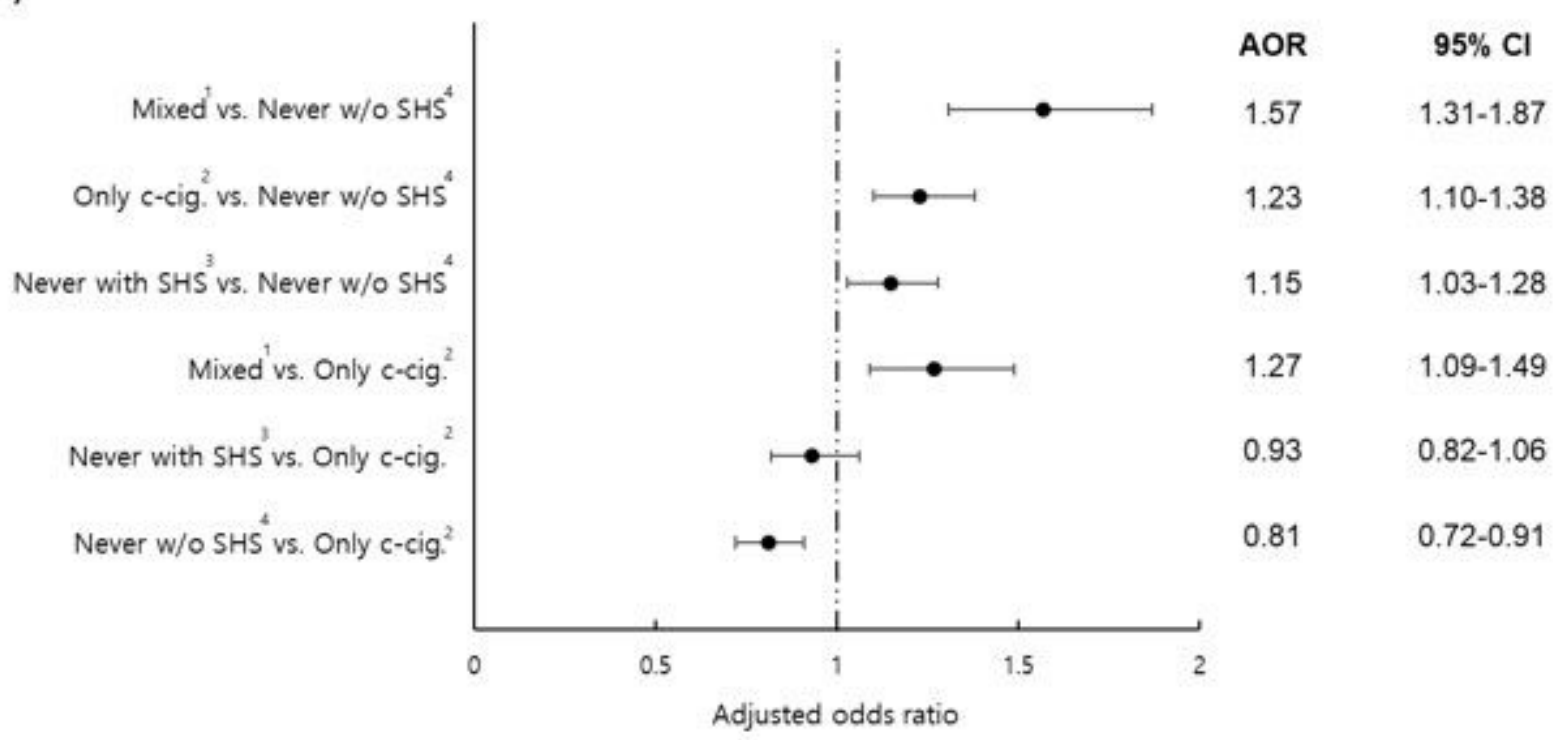

(B)

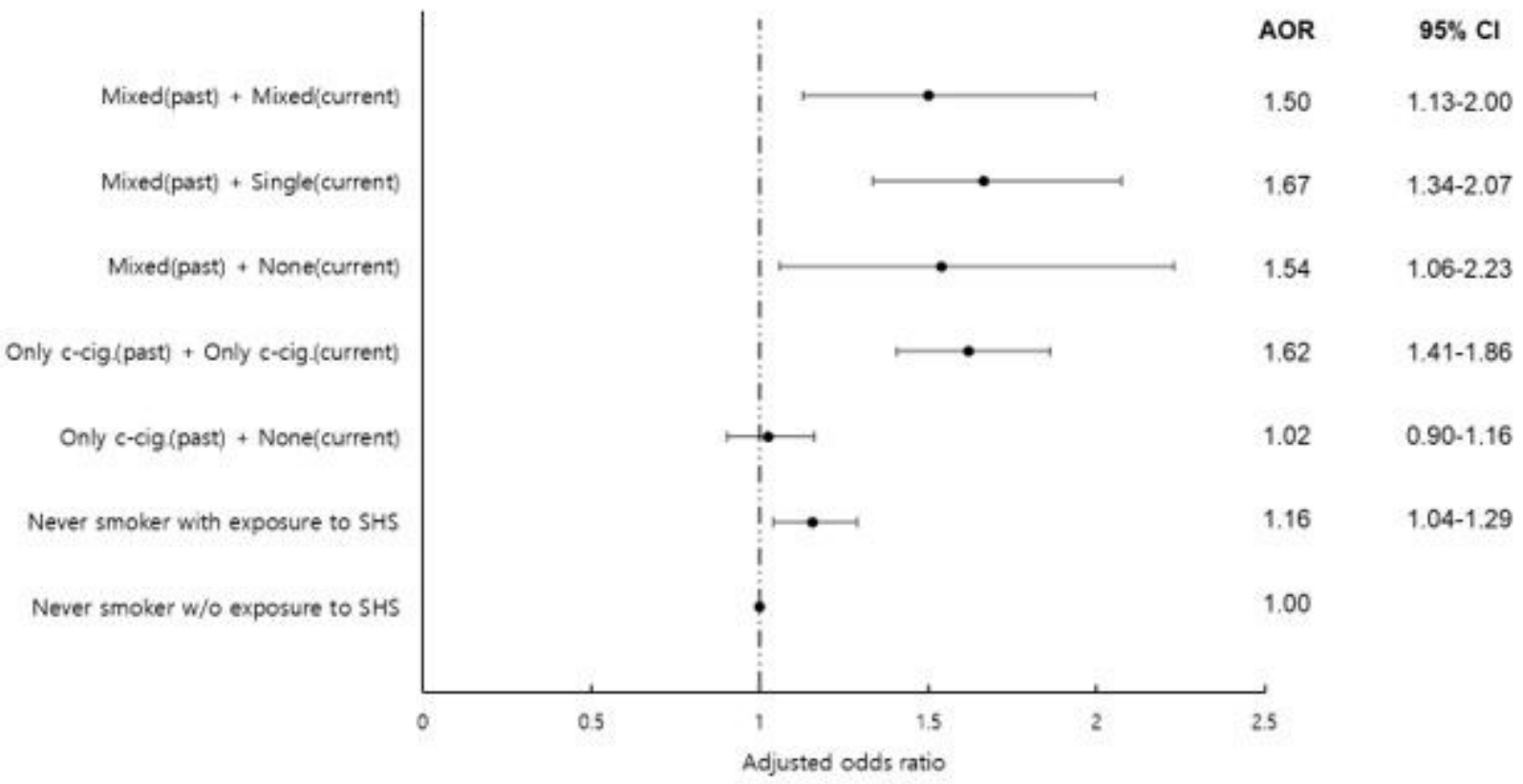

Figure 1

(A) Multivariate association between smoking behavior and prediabetes. (B) subgroup analysis of the main independent variable. w/o, without; c-cig., conventional cigarette; e-cig., electronic cigarette.1 Mixed user of electronic and conventional cigarette; 2 only conventional cigarette user; 3 Never smoker with secondhand smoke; 4 Never smoker without secondhand smoke. SHS: secondhand smoke. 